\title{
Technical note: Development and validation of an HPLC method for the quantification of tocopherols in different types of commercial cow milk
}

\author{
G. Niero, ${ }^{* 1}$ M. Penasa, ${ }^{*}$ J. Berard, †‡ M. Kreuzer,† M. Cassandro, ${ }^{*}$ and M. De Marchi* \\ *Department of Agronomy, Food, Natural Resources, Animals and Environment, University of Padova, Viale dell'Università 16, \\ 35020 Legnaro (PD), Italy \\ †ETH Zurich, Institute of Agricultural Sciences, Universitätstrasse 2, 8092 Zurich, Switzerland \\ ‡ETH Zurich, AgroVet-Strickhof, Eschikon 27, 8315 Lindau, Switzerland
}

\section{ABSTRACT}

In the present study, a methanol-fluorescence-based HPLC method was validated for its use to quantify $\alpha$-tocopherol and $\gamma$-tocopherol in raw milk, whole UHT milk, partially skimmed UHT milk, whole pasteurized milk, and partially skimmed pasteurized milk. Repeatability and reproducibility, calculated as relative standard deviation of 10 measurements within the same day and 30 measurements across $3 \mathrm{~d}$, respectively, were always below $5 \%$ for both tocopherols concentrations and retention times. Recovery was assessed through 3 spiking levels and it ranged from 89 to $107 \%$. The method was able to detect the expected declines in tocopherols in milk exposed to UHT or skimming treatments. Vitamin E, calculated as the sum of $\alpha$-tocopherol and $\gamma$-tocopherol, was similar in whole pasteurized and raw milk, averaging 1.57 and $1.56 \mathrm{mg} / \mathrm{L}$, respectively, followed by whole UHT $(1.33 \mathrm{mg} / \mathrm{L})$, partially skimmed pasteurized $(0.77 \mathrm{mg} / \mathrm{L})$, and partially skimmed UHT milk $(0.61 \mathrm{mg} / \mathrm{L})$.

Key words: milk, tocopherol, UHT, skimming

\section{Technical Note}

Tocopherols are among the major fat-soluble antioxidants and they exist in nature in 4 variants, namely $\alpha-$, $\beta-, \gamma-$, and $\delta$-tocopherol (T); together with tocotrienols, they belong to vitamin E compounds (Ju et al., 2010; Shehata et al., 2015). Both in vivo and in vitro studies demonstrated that tocopherols have direct and indirect antioxidant activity, and human epidemiological studies showed an association between low vitamin E status and an increased risk of cancer and heart diseases

Received November 23, 2017.

Accepted April 3, 2018.

${ }^{1}$ Corresponding author: giovanni.niero@studenti.unipd.it
(Galli et al., 2017). Tocopherols cannot be synthesized in human organisms, and therefore dietary sources are essential to reach the recommended daily requirement. Among the animal-derived foods, cow milk and milk products can be sources of these compounds (Guo et al., 2014) and they are worthy of scientific investigation for 2 main reasons. First, tocopherols are frequently used as additives in the diet of dairy cows to cover their requirements and to improve milk quality, health status, fertility, and productive performance (Baldi et al., 2000). Second, from a technological point of view, tocopherols play an important role in maintaining an oxidative stability of milk and dairy products, especially to protect and preserve oxidative stability of PUFA in milk fat (Havemose et al., 2006). Nevertheless, processing techniques, such as skimming and heating, may adversely affect the bioavailability of these compounds (Manzi and Pizzoferrato, 2010; Guneser and Yuceer, 2012). In the literature, several alkaline saponification procedures for milk tocopherols extraction, as well as HPLC protocols for tocopherols separation and detection, have been described. The majority of these procedures involve invasive and time-consuming sample pretreatment, such as the use of a rotovapor (Renzi et al., 2005), which might affect accuracy of the results. The chromatographic conditions are mainly based on toxic and expensive mobile phases, such as heptane, hexane (Ellis et al., 2007), acetonitrile, dichloromethane (Chauveau-Duriot et al., 2010), or triethylamine (Ramalho et al., 2012). Finally, UV and visible wavelengths are often used for detection, resulting in a weak signalto-noise ratio and a low sensibility (Renzi et al., 2005; Chauveau-Duriot et al., 2010; Guneser and Yuceer, 2012). The present work aimed to develop a fast milk sample preparation protocol avoiding the previously noted disadvantages and to validate a cost-effective HPLC separation program coupled with sensible fluorescence detection for quantification of tocopherols in different types of commercial cow milk. 


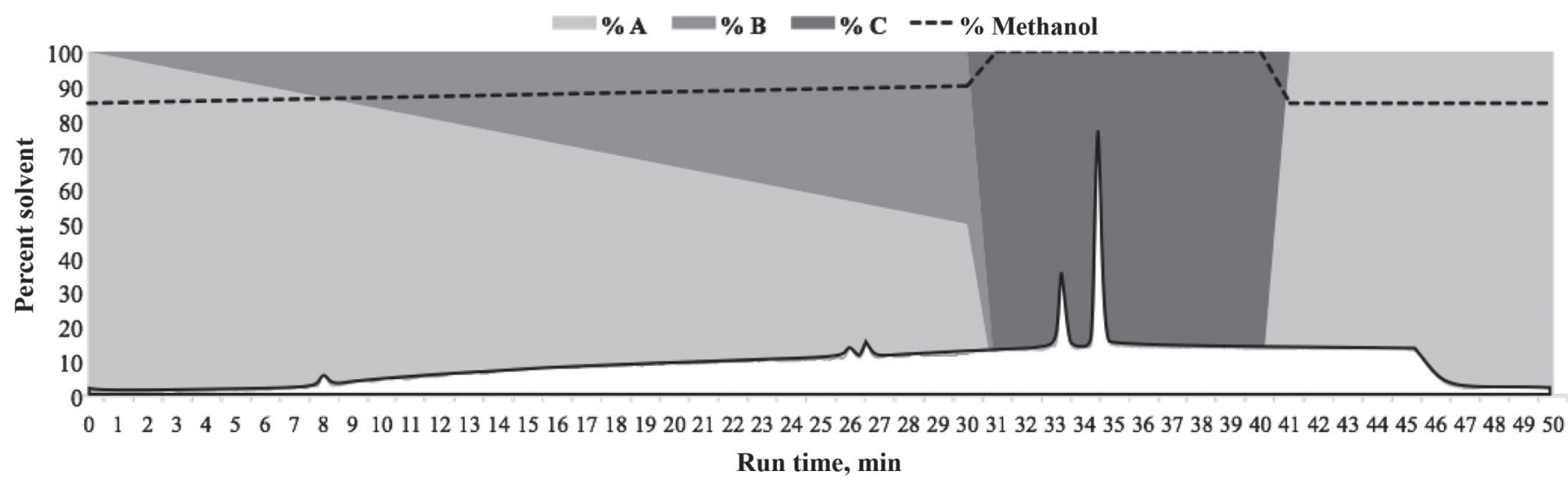

Figure 1. Elution program applied for the separation of milk tocopherols in HPLC (solvent A $=85 \%$ methanol, solvent B $=95 \%$ methanol, solvent $\mathrm{C}=100 \%$ methanol), overlaid with the chromatogram obtained from raw milk.

A raw milk (RM) sample was purchased in a vending machine (Zurich, Switzerland). Four milk samples of the same dairy brand, including whole UHT milk (WUM), partially skimmed UHT milk (SUM), whole pasteurized milk (WM), and partially skimmed pasteurized milk (SM), were purchased in a single local commercial store (Zurich, Switzerland). According to the nutritional labels, the fat contents were $3.7 \%$ (RM), $3.9 \%$ (WM and WUM), and $2.5 \%$ (SM and SUM). All samples were kept at $4^{\circ} \mathrm{C}$ and warmed at room temperature before analysis. Aliquots of $10 \mathrm{~mL}$ of milk were poured into screw-top glass vessels, and added to $1 \mathrm{~g}$ of ascorbate, $10 \mathrm{~mL}$ of methanol, and $10 \mathrm{~mL}$ of $0.18 \mathrm{M} \mathrm{KOH}$ in methanol and water (1:2). The resulting mixture was cooked in a water bath at $100^{\circ} \mathrm{C}$ for $1 \mathrm{~h}$ in hermetically closed vessels. Samples were cooled at room temperature and rinsed with $35 \%$ ethanol up to a volume of $100 \mathrm{~mL}$. An aliquot of 10 $\mathrm{mL}$ of this mixture was added to $3 \mathrm{~mL}$ of hexane and toluene (1:1), and gently shaken for $5 \mathrm{~min}$ to promote $\mathrm{T}$ extraction. Samples were centrifuged for $5 \mathrm{~min}$ at 2,500 $\times g$ at room temperature and $2 \mathrm{~mL}$ of the top organic phase were dried under nitrogen. Finally, samples were resuspended in $1 \mathrm{~mL}$ of methanol.

Milk tocopherols were detected and quantified through a quaternary pump HPLC device (Waters Alliance 2695; Waters Corporation, Milford, MA), equipped with a fluorescence detector (Waters Multi Fluorescence Detector 2475) and a reverse phase C18 column (Nucleodur PolarTec $250 \mathrm{~mm}, 3-\mu \mathrm{m}$ particle size; Macherey-Nagel, Düren, Germany). Samples were kept at $10^{\circ} \mathrm{C}$ in a refrigerated autosampler. Gradient elution was carried out with a mixture of 3 solvents (A, $\mathrm{B}$, and $\mathrm{C}$ ), which consisted of $85 \%$ (A) and $95 \%$ (B) of methanol in water and $100 \%(\mathrm{C})$ methanol. The elution program depicted in the background of Figure 1, was adjusted following column usage recommendations. The elution consisted of a linear gradient from 100 to $50 \% \mathrm{~A}$ and from 0 to $50 \% \mathrm{~B}$ in $30 \mathrm{~min}$, a linear gradient from 50 to $0 \%$ A, from 50 to $0 \% \mathrm{~B}$, and from 0 to $100 \%$ $\mathrm{C}$ in $1 \mathrm{~min}$, an isocratic elution at $100 \% \mathrm{C}$ for $9 \mathrm{~min}$, and a linear return to the starting condition within 1 min. Injection volume was $25 \mu \mathrm{L}$. Before injecting the following sample, the column was re-equilibrated under the starting conditions for $9 \mathrm{~min}$. The flow rate was 0.4 $\mathrm{mL} / \mathrm{min}$, the column temperature was kept at $30^{\circ} \mathrm{C}$, and the detection was carried out in fluorescence with an excitation wavelength of $295 \mathrm{~nm}$ and an emission wavelength of $330 \mathrm{~nm}$. Overall, 25 milk samples can be treated and prepared simultaneously in $4 \mathrm{~h}$, and the following HPLC analyses will last for about $20 \mathrm{~h}$. As a result, 25 milk samples can be analyzed in $24 \mathrm{~h}$ with the method described.

Standard solutions were prepared in methanol and quantification of each chromatographic peak was obtained with 5 -point calibration curves $\left(\mathrm{R}^{2} \geq 0.99\right)$. For $\alpha$ - $\mathrm{T}$ the lowest standard concentration was $0.20 \mathrm{mg} / \mathrm{L}$, followed by $2.00,3.00,4.00$, and $5.00 \mathrm{mg} / \mathrm{L}$. For $\gamma-\mathrm{T}$ the lowest standard concentration was $0.02 \mathrm{mg} / \mathrm{L}$, followed by $0.20,0.40,1.00$, and $2.00 \mathrm{mg} / \mathrm{L}$. Results were corrected by the recovery rate of $\delta$ - T, used as internal standard in a final concentration of $1.00 \mathrm{mg} / \mathrm{L}$, to cope with the underestimation due to the losses of target molecules.

Recovery of the method was assessed through 3 spiking levels of the starting milk. In particular, 0.01 and $0.0025 \mathrm{mg}, 0.02$ and $0.005 \mathrm{mg}$, and 0.04 and 0.01 $\mathrm{mg}$ of $\alpha-\mathrm{T}$ and $\gamma-\mathrm{T}$ standards were dissolved in $10 \mathrm{~mL}$ of methanol for spiking 1,2 and 3 , respectively. The obtained solutions were added to milk as described in the first step of milk sample preparation procedure and treated following the same protocol. The aliquots 
were mixed and split in 10 subaliquots processed separately, as previously described. Resolution $(\mathbf{R})$ of the method, defined as the quality of the separation of 2 neighbor peaks (1st and 2nd) was calculated according to Chauveau-Duriot et al. (2010) as

$$
\mathrm{R}=2 \times\left(\mathrm{Rt}_{2 \mathrm{nd}}-\mathrm{Rt}_{1 \mathrm{st}}\right) /\left(\mathrm{W}_{1 \mathrm{st}}+\mathrm{W}_{2 \mathrm{nd}}\right),
$$

where $\mathrm{Rt}_{1 \mathrm{st}}$ and $\mathrm{Rt}_{2 \mathrm{nd}}(\mathrm{min})$ are retention times, and $\mathrm{W}_{1 \mathrm{st}}$ and $\mathrm{W}_{2 \text { nd }}(\mathrm{min})$ are widths of the first and the second peaks, respectively. The sensitivity of the method was calculated as limit of detection (LOD), set at a signalto-noise ratio of 3:1, and limit of quantification (LOQ), set at a signal-to-noise ratio of 10:1 (Chauveau-Duriot et al., 2010). Repeatability was calculated as the relative standard deviation $\left(\mathbf{R S D}_{\mathbf{r}}\right)$ of 10 consecutive measures of the RM, WUM, SUM, WM, and SM samples within the same day, both for tocopherol concentration and retention time. Similarly, reproducibility was calculated as the relative standard deviation $\left(\mathbf{R S D}_{\mathbf{R}}\right)$ of 30 measures obtained across $3 \mathrm{~d}$ of analyses (Sturaro et al., 2016; Niero et al., 2017).

The chromatographic track obtained from RM (Figure 1), WUM, SUM, WM, and SM revealed 2 major peaks, corresponding to $\gamma-\mathrm{T}$ and $\alpha-\mathrm{T}$, being the first and the second in elution order and the minor and the major in signal abundance, respectively. On the other hand, chromatograms did not show any signal related to $\beta$-T and $\delta$-T, meaning that these tocopherol species are absent in milk. Findings of the present study were in agreement with results of Chauveau-Duriot et al. (2010), who reported that $\alpha-T$ was the major tocopherol in milk, whereas $\gamma$ - $\mathrm{T}$ was only detected in traces, without quantification. Finally, the present method did not allow the detection of tocotrienols that were previously observed in traces by Kaushik et al. (2001). This is likely due to the different detectors used in our study compared with the investigation of Kaushik et al. (2001).

Descriptive statistics of $\alpha-T$ and $\gamma-T$ content in RM, WUM, SUM, WM, and SM are shown in Table 1. The $\alpha-\mathrm{T}$ was numerically most concentrated in WM (mean of $1.41 \mathrm{mg} / \mathrm{L})$, followed by RM $(1.35 \mathrm{mg} / \mathrm{L})$, WUM $(1.18 \mathrm{mg} / \mathrm{L}), \mathrm{SM}(0.65 \mathrm{mg} / \mathrm{L})$, and SUM $(0.47 \mathrm{mg} / \mathrm{L})$. The average concentration of $\alpha-T$ in $R M$ observed in the present work was close to values reported by Baldi et al. (2000), Nozière et al. (2006), and Guneser and Yuceer (2012). On the other hand, lower milk tocopherol concentrations were reported by Havemose et al. (2006). The greatest numerical concentration of $\gamma$-T was measured in RM (mean of $0.21 \mathrm{mg} / \mathrm{L}$ ), followed by WM $(0.16 \mathrm{mg} / \mathrm{L}), \mathrm{WUM}(0.15 \mathrm{mg} / \mathrm{L})$, and SUM (0.14 $\mathrm{mg} / \mathrm{L})$. The milk numerically poorest in $\gamma-\mathrm{T}$ content was SM $(0.12 \mathrm{mg} / \mathrm{L})$. The overall amount of vitamin $\mathrm{E}$ in milk, calculated as the sum of $\alpha-\mathrm{T}$ and $\gamma$-T concentrations (Shehata et al., 2015), was numerically similar in WM (mean of $1.57 \mathrm{mg} / \mathrm{L}$ ) and RM (mean of 1.56 $\mathrm{mg} / \mathrm{L})$ and was higher than that of WUM $(1.33 \mathrm{mg} / \mathrm{L})$ and SM $(0.77 \mathrm{mg} / \mathrm{L})$. The lowest vitamin $\mathrm{E}$ content was observed in SUM, with a mean of $0.61 \mathrm{mg} / \mathrm{L}$. The vitamin E content of RM from cows was somewhat higher than that of buffaloes (Spagnuolo et al., 2003), but lower than that of goats (Guneser and Yuceer, 2012) and yaks (Guo et al., 2014). These differences might be related to the different fat content of the milk samples, as well as the different physiological mechanisms and efficiencies involved in vitamin $\mathrm{E}$ transportation from feed to blood and from blood to milk (Kalač, 2012). Animal diets and farming systems are important factors influencing milk tocopherols content as well. Shingfield et al. (2005) reported that $\alpha-T$ content increased about 2 fold in milk from cows fed hay compared with cows fed grass silages, and Bergamo et al. (2003) observed a significant increase of $\alpha-T$ in organic dairy products compared with conventional products. Finally, one of the most important dietary factor of influence on the tocopherol levels in milk is the amount of tocopherols given through animal mineral supplements (Focant et al., 1998). The expected effect of skimming treatment on the lipophilic milk tocopherol concentration (Manzi and Pizzoferrato, 2010) was found when comparing WM with SM (declines of 54 and $25 \%$ in $\alpha-\mathrm{T}$ and $\gamma-\mathrm{T}$, respectively) and WUM with SUM (declines of 60 and $6.7 \%$ in $\alpha-\mathrm{T}$ and $\gamma-\mathrm{T}$, respectively; Table 1 ). The adverse effect of UHT treatment on vitamin E (Guneser

Table 1. Descriptive statistics of $\alpha$-tocopherol and $\gamma$-tocopherol in milk $(\mathrm{mg} / \mathrm{L} ; \mathrm{n}=30)^{1}$

\begin{tabular}{|c|c|c|c|}
\hline Milk $^{2}$ & Mean & Minimum & Maximum \\
\hline \multicolumn{4}{|l|}{ RM } \\
\hline$\alpha$-tocopherol & 1.35 & 1.25 & 1.42 \\
\hline$\gamma$-tocopherol & 0.21 & 0.20 & 0.22 \\
\hline \multicolumn{4}{|l|}{ WUM } \\
\hline$\alpha$-tocopherol & 1.18 & 1.10 & 1.26 \\
\hline$\gamma$-tocopherol & 0.15 & 0.14 & 0.16 \\
\hline \multicolumn{4}{|l|}{ SUM } \\
\hline$\alpha$-tocopherol & 0.47 & 0.44 & 0.52 \\
\hline$\gamma$-tocopherol & 0.14 & 0.10 & 0.12 \\
\hline \multicolumn{4}{|l|}{ WM } \\
\hline$\alpha$-tocopherol & 1.41 & 1.33 & 1.54 \\
\hline$\gamma$-tocopherol & 0.16 & 0.15 & 0.17 \\
\hline \multicolumn{4}{|l|}{ SM } \\
\hline$\alpha$-tocopherol & 0.65 & 0.59 & 0.69 \\
\hline$\gamma$-tocopherol & 0.12 & 0.11 & 0.13 \\
\hline
\end{tabular}

${ }^{1}$ Each milk sample was analyzed 10 times a day during $3 \mathrm{~d}$.

${ }^{2} \mathrm{RM}=$ raw milk; WUM = whole UHT milk; SUM = partially skimmed UHT milk; WM = whole pasteurized milk; SM = partially skimmed pasteurized milk. 
and Yuceer, 2012) was found in whole milk and skim milk, with declines of 16 and $6.3 \%$ in $\alpha$-T and $\gamma-\mathrm{T}$ concentration with whole milk, respectively, and $28 \%$ in $\alpha-T$ concentration in skim milk, where no difference in $\gamma$ - $\mathrm{T}$ concentration was found.

Considering the cleanness of the whole chromatogram, the almost total absence of background noise and interference signals, and the complete separation of the 2 chromatographic peaks corresponding to the target molecules, we can affirm that the proposed method showed a high specificity for these 2 milk tocopherols (ICH Harmonised Tripartite Guideline, 2005; Figure 1). The resolution between $\alpha-T$ and $\gamma-T$ chromatographic peaks in RM, WUM, SUM, WM, and SM ranged from 1.83 to 2.12, thus exhibiting an overall greater separation performance compared with HPLC (1.43) and UPLC (1.93) applications proposed by Chauveau-Duriot et al. (2010). Limit of detection and LOQ calculated through standard solutions were 0.15 and $0.50 \mathrm{ng} / \mathrm{mL}$ for $\alpha-\mathrm{T}$ and 0.24 and $0.80 \mathrm{ng} /$ $\mathrm{mL}$ for $\gamma-\mathrm{T}$, respectively. The minimum concentration of $\alpha-\mathrm{T}$ found in the present study was 85 fold that of LOD, and the lowest concentration of $\gamma$-T was 12 times the LOD; thus, optimal confidence level and sensitivity were provided. The present method showed greater specificity and sensitivity compared with HPLC- and UPLC-based protocols developed by Chauveau-Duriot et al. (2010). The improvements reached in the present study could be partially due to analytical precautions that were adopted; namely (1) a less invasive procedure for milk sample preparation compared with other, laborious saponification protocols involving repeated extractions phases and rotary evaporator (Ellis et al., 2007; Guneser and Yuceer, 2012), and (2) high specificity and sensitivity of fluorescence used for tocopherols detection (Niero et al., 2015) instead of the less specific $\mathrm{UV}$ and visible wavelengths.

Table 2 shows repeatability and reproducibility obtained for $\alpha-T$ and $\gamma-T$ quantification. Values of $\mathrm{RSD}_{\mathrm{r}}$ indicated a high repeatability for each type of commercial milk, ranging from $1.65 \%$ for $\mathrm{RM} \gamma-\mathrm{T}$ on $\mathrm{d} 3$ to $4.09 \%$ for SUM $\gamma-\mathrm{T}$ on d 3 , and values of $\mathrm{RSD}_{\mathrm{R}}$ suggested a high reproducibility, ranging from $2.62 \%$ (RM) to $4.45 \%$ (SUM). Therefore, in accordance with results of Sturaro et al. (2016) and Niero et al. (2017), a slight decline in accuracy was found between days compared with the accuracy observed within day (Supplemental Figure S1; https://doi.org/10.3168/jds.2017-14187). Repeatability and reproducibility were even more accurate for retention times of $\alpha-\mathrm{T}$ and $\gamma-\mathrm{T}$ (Supplemental Table S1; https://doi.org/10.3168/jds.2017-14187): the $\mathrm{RSD}_{\mathrm{r}}$ ranged from 0.02 to $1.14 \%$, and the $\mathrm{RSD}_{\mathrm{R}}$ was always below $1 \%$, ranging from 0.04 to $0.87 \%$. Recovery tests reached the greatest values for the first spiking level in SUM, scoring 105 and $107 \%$ for $\alpha-T$ and $\gamma-\mathrm{T}$, respectively, whereas the lowest recoveries were observed in the third spiking level for $\gamma$-T, averaging 89 and $91 \%$ in SUM and WUM, respectively (Table 3). For RM, WUM, SUM, and SM, a slight decline in recovery percentages was observed for higher spiking levels. Accordingly, the recovery was most generally efficient for low spiking levels. This phenomenon might be partially due to the saturation of the solvents used for milk sample preparation at the high spiking levels.

Table 2. Relative standard deviation of repeatability $\left(\mathrm{RSD}_{\mathrm{r}}, \% ; \mathrm{n}=10\right)$ and relative standard deviation of reproducibility $\left(\mathrm{RSD}_{\mathrm{R}}, \% ; \mathrm{n}=30\right)$ for mean concentrations $(\mathrm{mg} / \mathrm{L})$ of $\alpha$-tocopherol and $\gamma$-tocopherol in milk

\begin{tabular}{|c|c|c|c|c|c|c|c|}
\hline \multirow[b]{2}{*}{ Milk $^{1}$} & \multicolumn{2}{|c|}{ Day 1} & \multicolumn{2}{|c|}{ Day 2} & \multicolumn{2}{|c|}{ Day 3} & \multirow[b]{2}{*}{$\mathrm{RSD}_{\mathrm{I}}$} \\
\hline & Mean & $\mathrm{RSD}_{\mathrm{r}}$ & Mean & $\mathrm{RSD}_{\mathrm{r}}$ & Mean & $\mathrm{RSD}_{\mathrm{r}}$ & \\
\hline \multicolumn{8}{|l|}{ RM } \\
\hline$\alpha$-tocopherol & 1.37 & 2.26 & 1.37 & 2.69 & 1.32 & 3.46 & 3.21 \\
\hline$\gamma$-tocopherol & 0.21 & 2.89 & 0.21 & 3.13 & 0.21 & 1.65 & 2.62 \\
\hline \multicolumn{8}{|l|}{ WUM } \\
\hline$\alpha$-tocopherol & 1.22 & 2.36 & 1.17 & 3.88 & 1.15 & 2.74 & 3.82 \\
\hline$\gamma$-tocopherol & 0.15 & 3.01 & 0.15 & 3.01 & 0.14 & 3.19 & 3.41 \\
\hline \multicolumn{8}{|l|}{ SUM } \\
\hline$\alpha$-tocopherol & 0.46 & 3.72 & 0.47 & 2.74 & 0.49 & 4.52 & 4.45 \\
\hline$\gamma$-tocopherol & 0.11 & 3.52 & 0.10 & 3.36 & 0.10 & 4.09 & 4.36 \\
\hline \multicolumn{8}{|l|}{ WM } \\
\hline$\alpha$-tocopherol & 1.45 & 3.59 & 1.38 & 3.28 & 1.40 & 2.24 & 3.70 \\
\hline$\gamma$-tocopherol & 0.16 & 2.87 & 0.16 & 3.86 & 0.16 & 3.88 & 3.60 \\
\hline \multicolumn{8}{|l|}{$\mathrm{SM}$} \\
\hline$\alpha$-tocopherol & 0.65 & 3.54 & 0.65 & 3.64 & 0.66 & 3.14 & 3.42 \\
\hline$\gamma$-tocopherol & 0.12 & 3.04 & 0.12 & 3.36 & 0.12 & 3.33 & 3.61 \\
\hline
\end{tabular}

${ }^{1} \mathrm{RM}=$ raw milk; WUM $=$ whole UHT milk; SUM = partially skimmed UHT milk; WM = whole pasteurized milk; SM = partially skimmed pasteurized milk. 
Table 3. Recovery $(\%)$ and relative standard deviation of repeatability $\left(\mathrm{RSD}_{\mathrm{r}}, \% ; \mathrm{n}=10\right)$ for $\alpha$-tocopherol and $\gamma$-tocopherol in milk

\begin{tabular}{|c|c|c|c|c|c|c|}
\hline \multirow[b]{2}{*}{ Milk $^{1}$} & \multicolumn{2}{|c|}{ Spike level 1} & \multicolumn{2}{|c|}{ Spike level 2} & \multicolumn{2}{|c|}{ Spike level 3} \\
\hline & Recovery & $\mathrm{RSD}_{\mathrm{r}}$ & Recovery & $\mathrm{RSD}_{\mathrm{r}}$ & Recovery & $\mathrm{RSD}_{\mathrm{r}}$ \\
\hline \multicolumn{7}{|l|}{$\mathrm{RM}$} \\
\hline$\alpha$-tocopherol & 98.5 & 2.56 & 95.3 & 1.89 & 93.7 & 3.21 \\
\hline$\gamma$-tocopherol & 96.2 & 3.63 & 96.0 & 3.37 & 92.1 & 2.62 \\
\hline \multicolumn{7}{|l|}{ WUM } \\
\hline$\alpha$-tocopherol & 101.5 & 1.98 & 93.1 & 3.78 & 95.9 & 3.48 \\
\hline$\gamma$-tocopherol & 94.6 & 3.67 & 94.3 & 2.24 & 91.4 & 2.76 \\
\hline \multicolumn{7}{|l|}{ SUM } \\
\hline$\alpha$-tocopherol & 104.8 & 2.97 & 101.2 & 2.17 & 96.3 & 2.82 \\
\hline$\gamma$-tocopherol & 106.6 & 3.31 & 96.3 & 1.86 & 89.2 & 2.75 \\
\hline \multicolumn{7}{|l|}{ WM } \\
\hline$\alpha$-tocopherol & 92.3 & 1.77 & 92.2 & 2.20 & 94.0 & 2.02 \\
\hline$\gamma$-tocopherol & 95.3 & 2.73 & 95.6 & 2.13 & 95.2 & 3.81 \\
\hline \multicolumn{7}{|l|}{ SM } \\
\hline$\alpha$-tocopherol & 103.2 & 3.00 & 95.4 & 2.99 & 95.6 & 3.50 \\
\hline$\gamma$-tocopherol & 104.8 & 1.92 & 100.3 & 2.12 & 100.8 & 2.43 \\
\hline
\end{tabular}

${ }^{1} \mathrm{RM}=$ raw milk; WUM $=$ whole UHT milk; SUM $=$ partially skimmed UHT milk; WM $=$ whole pasteurized milk; SM $=$ partially skimmed pasteurized milk.

In conclusion, a simple and fast saponification protocol followed by a cheap HPLC method based on methanol elution and sensible fluorescence detection was validated for the quantification of $\alpha-T$ and $\gamma-T$ in different types of commercial fluid milk. $\alpha$-Tocopherol was the major tocopherol in milk. Our method was able to detect the adverse effects of skimming and UHT treatment on $\alpha-\mathrm{T}$ and $\gamma-\mathrm{T}$, and it could be usefully adopted in future for large-scale studies aiming to investigate phenotypic variation of tocopherols in milk.

\section{ACKNOWLEDGMENTS}

The research was funded by "Investimento Strategico di Dipartimento - SID 2017" (University of Padova), project BIRD163298/16 "Studio degli aspetti fenotipici e genetici del contenuto di $\alpha, \beta$, $\gamma$ e $\delta$ Tocoferolo (TC) nel latte di bovine di razza Frisona Italiana" (Padova, Italy).

\section{REFERENCES}

Baldi, A., G. Savoini, L. Pinotti, E. Monfardini, F. Cheli, and V. D. Orto. 2000. Effects of vitamin $\mathrm{E}$ and different energy sources on vitamin E status, milk quality and reproduction in transition cows. J. Vet. Med. A Physiol. Pathol. Clin. Med. 47:599-608.

Bergamo, P., E. Fedele, L. Iannibelli, and G. Marzillo. 2003. Fat-soluble vitamin contents and fatty acid composition in organic and conventional Italian dairy products. Food Chem. 82:625-631.

Chauveau-Duriot, B., M. Doreau, P. Nozière, and B. Graulet. 2010. Simultaneous quantification of carotenoids, retinol, and tocopherols in forages, bovine plasma, and milk: Validation of a novel UPLC method. Anal. Bioanal. Chem. 397:777-790.

Ellis, K. A., A. Monteiro, G. T. Innocent, D. Grove-White, P. Cripps, W. G. McLean, C. V. Howard, and M. Mihm. 2007. Investigation of the vitamins $\mathrm{A}$ and $\mathrm{E}$ and $\beta$-carotene content in milk from UK organic and conventional dairy farms. J. Dairy Res. 74:484-491.

Focant, M., E. Mignolet, M. Marique, F. Clabots, T. Breyne, D. Dalemans, and Y. Larondelle. 1998. The effect of vitamin E supplementation of cow diets containing rapeseed and linseed on the prevention of milk fat oxidation. J. Dairy Sci. 81:1095-1101.

Galli, F., A. Azzi, M. Birringer, J. M. Cook-Mills, M. Eggersdorfer, J. Frank, G. Cruciani, S. Lorkowski, and N. K. Özer. 2017. Vitamin E: Emerging aspects and new directions. Free Radic. Biol. Med. $102: 16-36$

Guneser, O., and Y. K. Yuceer. 2012. Effect of ultraviolet light on water-and fat-soluble vitamins in cow and goat milk. J. Dairy Sci. 95:6230-6241

Guo, X., R. Long, M. Kreuzer, L. Ding, Z. Shang, Y. Zhang, Y. Yang, and G. Cui. 2014. Importance of functional ingredients in yak milk-derived food on health of Tibetan nomads living under highaltitude stress: a review. Crit. Rev. Food Sci. Nutr. 54:292-302.

Harmonised Tripartite Guideline, I. C. H. 2005. Q2(R1): Validation of analytical procedures: Text and methodology. Pages 11-12 in International Conference on Harmonisation of Technical Requirements for Registration of Pharmaceuticals for Human Use, Geneva, Switzerland.

Havemose, M. S., M. R. Weisbjerg, W. L. P. Bredie, H. D. Poulsen, and J. H. Nielsen. 2006. Oxidative stability of milk influenced by fatty acids, antioxidants, and copper derived from feed. J. Dairy Sci. 89:1970-1980.

Ju, J., S. C. Picinich, Z. Yang, Y. Zhao, N. Suh, A. N. Kong, and C. S. Yang. 2010. Cancer-preventive activities of tocopherols and tocotrienols. Carcinogenesis 31:533-542.

Kalač, P. 2012. Carotenoids, ergosterol and tocopherols in fresh and preserved herbage and their transfer to bovine milk fat and adipose tissues: a review. J. Agrobiol. 29:1-13.

Kaushik, S., R. Wander, S. Leonard, B. German, and M. G. Traber. 2001. Removal of fat from cow's milk decreases the vitamin $\mathrm{E}$ contents of the resulting dairy products. Lipids 36:73-78.

Manzi, P., and L. Pizzoferrato. 2010. Cholesterol and antioxidant vitamins in fat fraction of whole and skimmed dairy products. Food Bioprocess Technol. 3:234-238.

Niero, G., M. De Marchi, A. Masi, M. Penasa, and M. Cassandro. 2015. Short communication: Characterization of soluble thiols in bovine milk. J. Dairy Sci. 98:6014-6017.

Niero, G., M. Penasa, S. Currò, A. Masi, A. R. Trentin, M. Cassandro, and M. De Marchi. 2017. Development and validation of a near in- 
frared spectrophotometric method to determine total antioxidant activity of milk. Food Chem. 220:371-376.

Nozière, P., P. Grolier, D. Durand, A. Ferlay, P. Pradel, and B. Martin. 2006. Variations in carotenoids, fat-soluble micronutrients, and color in cows' plasma and milk following changes in forage and feeding level. J. Dairy Sci. 89:2634-2648.

Ramalho, H. M. M., J. Santos, S. Casal, M. R. Alves, and M. B. P. P. Oliveira. 2012. Fat-soluble vitamin (A, D, E, and $\beta$-carotene) contents from a Portuguese autochthonous cow breed-Minhota. J. Dairy Sci. 95:5476-5484.

Renzi, M., F. Righi, C. Quarantelli, A. Quarantelli, and A. Bonomi. 2005. Simplified HPLC-UV method for the determination of $\alpha$-tocopherol in plasma. Ital. J. Anim. Sci. 4:191-195.

Shehata, A. B., M. S. Rizk, A. M. Farag, and I. F. Tahoun. 2015. Development of two reference materials for all trans-retinol, retinyl palmitate, $\alpha$ - and $\gamma$-tocopherol in milk powder and infant formula. J. Food Drug Anal. 23:82-92.

Shingfield, K. J., P. Salo-Väänänen, E. Pahkala, V. Toivonen, S. Jaakkola, V. Piironen, and P. Huhtanen. 2005. Effect of forage conservation, concentrate level and propylene glycol on the fatty acid composition and vitamin content of cow's milk. J. Dairy Res. 72:349-361.

Spagnuolo, M. S., L. Cigliano, F. Sarubbi, F. Polimeno, L. Ferrara, G. Bertoni, and P. Abrescia. 2003. The accumulation of $\alpha$-tocopherol and retinol in the milk of water buffalo is correlated with the plasma levels of triiodothyronine. Biofactors 19:197-209.

Sturaro, A., M. De Marchi, A. Masi, and M. Cassandro. 2016. Quantification of whey proteins by reversed phase-HPLC and effectiveness of mid-infrared spectroscopy for their rapid prediction in sweet whey. J. Dairy Sci. 99:68-76. 